\title{
Considerations Regarding the Negative Prices on the Electricity Market ${ }^{\dagger}$
}

\author{
Pavel Atănăsoae *(i), Radu Dumitru Pentiuc and Eugen Hopulele \\ Faculty of Electrical Engineering and Computer Science, Stefan cel Mare University of Suceava, Universitatii 13, \\ 720229 Suceava, Romania; radup@eed.usv.ro (R.D.P.); eugenh@eed.usv.ro (E.H.) \\ * Correspondence: atanasoae@eed.usv.ro; Tel.: +40-721-246-229 \\ + Presented at the 14th International Conference on Interdisciplinarity in Engineering-INTER-ENG 2020, \\ Târgu Mureș, Romania, 8-9 October 2020.
}

Published: 16 December 2020

\begin{abstract}
Increasing of intermittent production from renewable energy sources significantly affects the distribution of electricity prices. In this paper, we analyze the impact of renewable energy sources on the formation of electricity prices on the Day-Ahead Market (DAM). The case of the 4M Market Coupling Project is analyzed: Czech-Slovak-Hungarian-Romanian market areas. As a result of the coupling of electricity markets and the increasing share of renewable energy sources, different situations have been identified in which prices are very volatile.
\end{abstract}

Keywords: electricity market; renewable energy; negative prices; price coupling of regions; day ahead market

\section{Introduction}

Electricity cannot be stored economically on a large scale and in appreciable quantities that would influence the operation of the power systems. Therefore, at all times, the supply injected into the network must be strictly equal to the demand and energy losses in the transmission and distribution networks. This explains why in the spot market, where prices are negotiated hourly, the price of electricity is very volatile [1].

Most European countries have chosen to accelerate the penetration of renewable energies into the electricity mix ( $20 \%$ by 2020 ). The production of electricity from renewable energy sources is supported by various support schemes [2-4]. To encourage the development of renewable energy sources, European countries have adopted a priority injection system that guarantees them access to the grid as soon as they produce electricity. This injection priority changes the way different means of production are used.

Increasing the production of electricity from renewable energy sources creates new challenges. The electricity generated by wind and solar energy is intermittent and difficult to predict, as it strongly depends on weather conditions [5]. Decision makers face various economic and technological challenges because renewable energy support instruments have a distortionary impact on electricity prices [6]. More specialized studies try through different models to anticipate the variation of prices on the energy markets in conditions of uncertainty. In the paper [7], the behavior of wind power producers adopting two different bidding modes in day-ahead electricity market is modeled and experimentally compared. The merit order effect for the Hellenic electricity market is analyzed in the paper [8]. Minimizing market risks and increasing profits are the main objectives of the market participants. Therefore, forecasting market prices is a challenge for all stakeholders [9-11]. As the supply and demand of electricity must be constantly balanced, the price varies depending on consumer behavior, climatic conditions or even compliance with the production schedules of 
power plants. Prices fall in the event of a decrease in demand or a surplus of production compared to forecasts and an increase in the opposite case [12-14]. The issue of forecasting consumption and production levels is therefore crucial. Supply cannot always be adjusted to demand a few hours earlier, especially because electricity is difficult to store on a large scale. The increasing integration of intermittent production capacities, such as wind turbines and photovoltaic systems, makes this adjustment even more difficult to control.

\section{Coupling of the Electricity Markets}

Price Coupling of Regions (PCR) is based on a single price coupling solution to be used for the calculation of electricity prices between coupled energy markets. The Day Ahead Market (DAM) from Romania operates in a regime coupled with spot markets in Hungary (HU), Slovakia (SK) and the Czech Republic (CZ) inside the 4M Market Coupling project starting with 2014 (Figure 1a). As well, starting with 19 November 2019, the Intra-Day Market (IDM) from Romania operates in conjunction with the markets in the other 20 countries (Figure 1b) participating in the European project SIDC (Single Intra-Day Coupling).

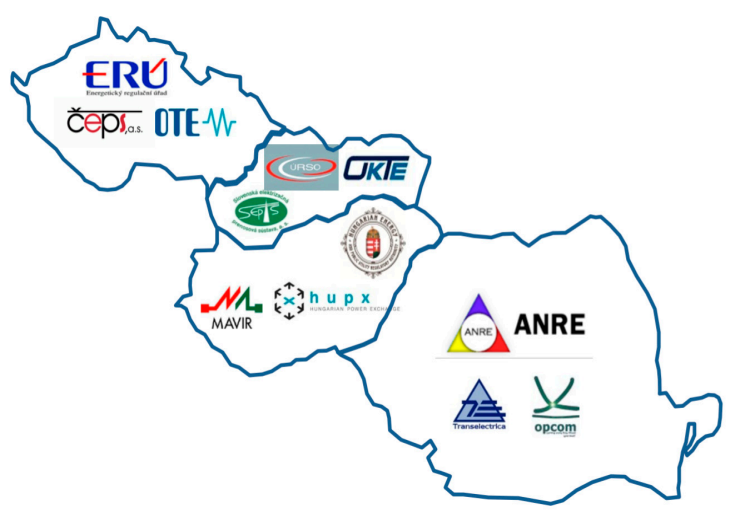

(a)

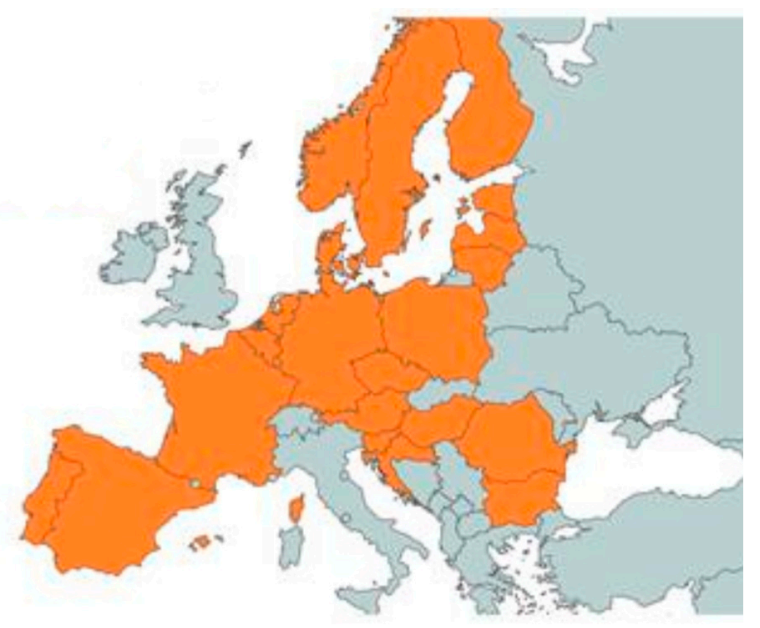

(b)

Figure 1. Coupling of the Electricity Markets: (a) The Day Ahead Market (DAM); (b) The Intra-Day Market (IDM); (Source: http://www.opcom.ro).

On the Day-Ahead Market are concluded on each trading day, firm transactions with electricity for each trading hour of the next delivery day, based on the offers submitted by the DAM participants. Transactions on the Intra-Day Market start with the day before delivery day, after the Day-Ahead Market trading has finished, and ends with an hour before starting the delivery.

\section{Analysis of the Electricity Prices on DAM: Case of the 4M Market Coupling}

Electrical network interconnections are a key element in regulating the European energy market, both for import and export. They allow for mutual assistance between the Member States of the Union, depending on the profiles of the respective consumers and their production capacities. This system makes it possible to strengthen the security of supply of the territory. At the same time, suppliers get the best price for energy at any time on the wholesale market.

The objective of the market coupling mechanism is to ensure the use of interconnections in the right direction, that is, from the market where energy is the cheapest to the most expensive. The only limit to the coupling of markets is given the import and export capacities at the borders. Network administrators set a limit to ensure security of supply. This limit cannot be exceeded by exporters. 
Thus, based on flows, it makes it possible to provide the most useful exchanges in the service of the network, by finding the best solutions between the countries concerned. The establishment of this system, however, required the harmonization of national rules governing the various integrated networks [15-17].

Even after the coupling of the energy markets, a variation in very large limits of the electricity prices is observed. Thus, several situations were identified with very high prices (Figures 2 and 3), with very low prices (Figures 4 and 5) and even negative (Figures 6 and 7). These situations were analyzed in comparison with the electricity production of Romania and with the energy exchanges and available transmission capacities existing on the border (Tables 1-3).

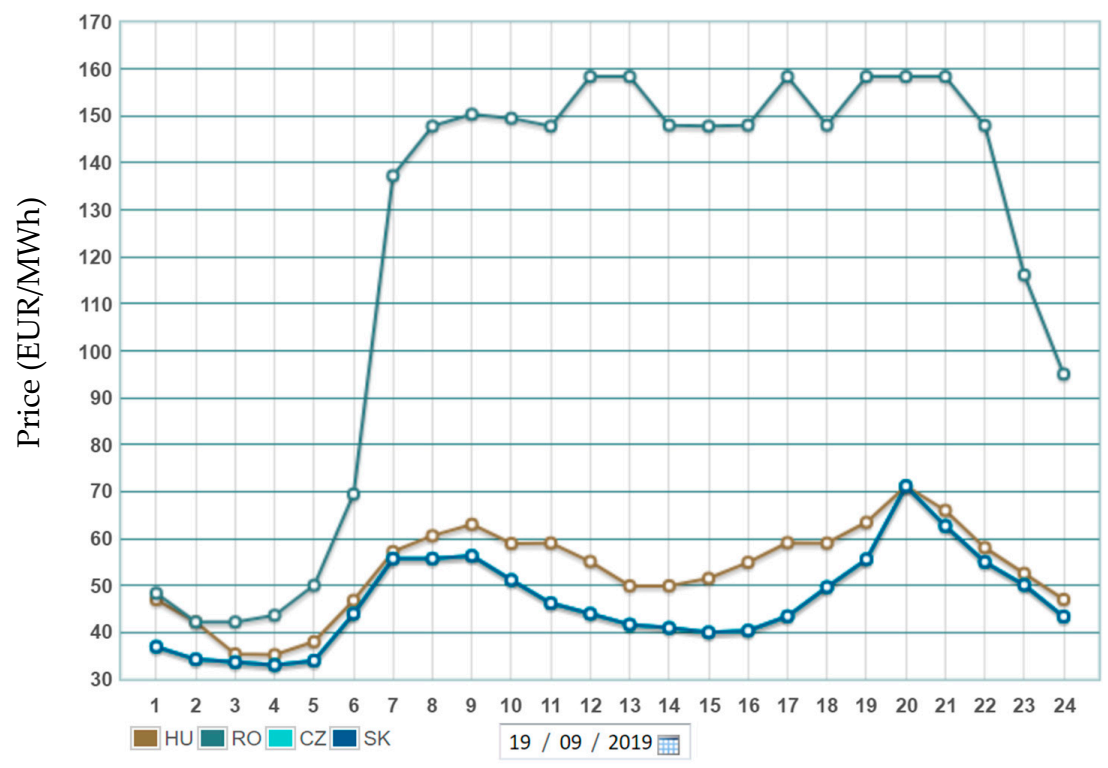

Figure 2. High prices on coupled electricity markets at the RO-HU border (data processed from website: http://www.opcom.ro).

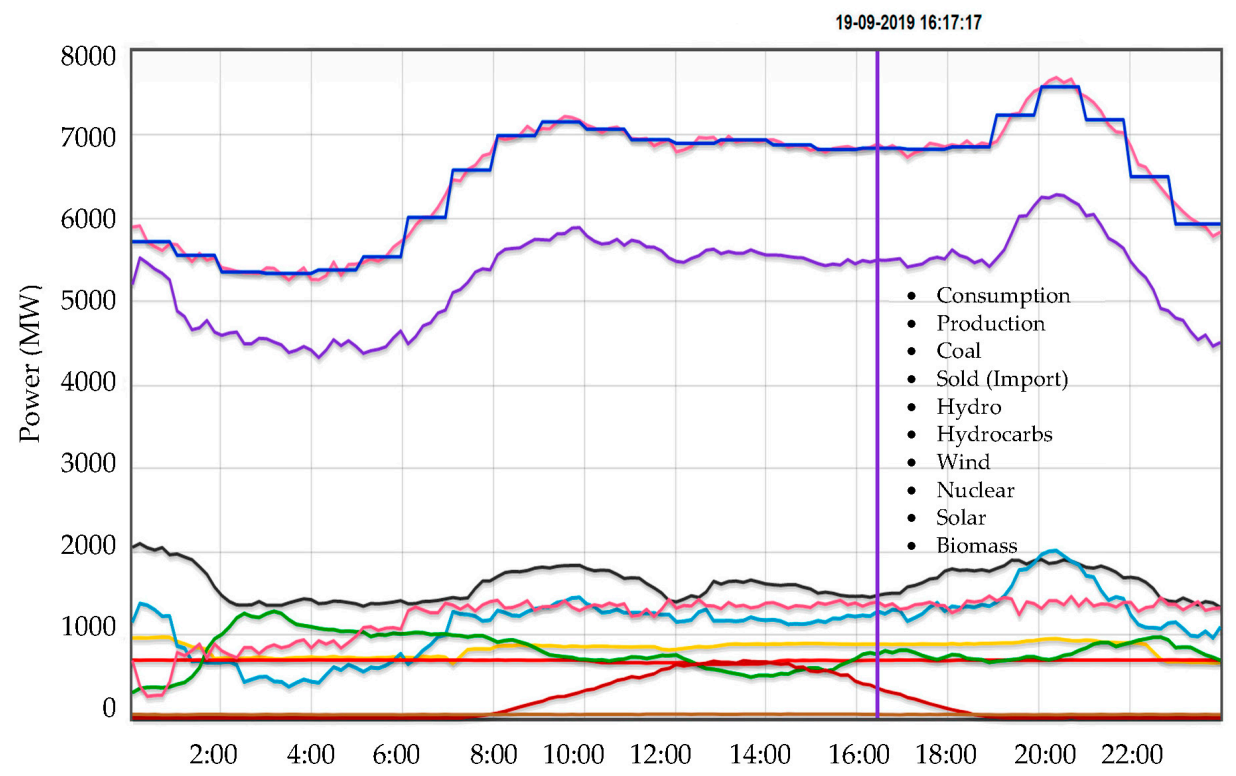

Figure 3. Electricity production in Romania on 19 September 2019 (data processed from website: http://www.transelectrica.ro). 


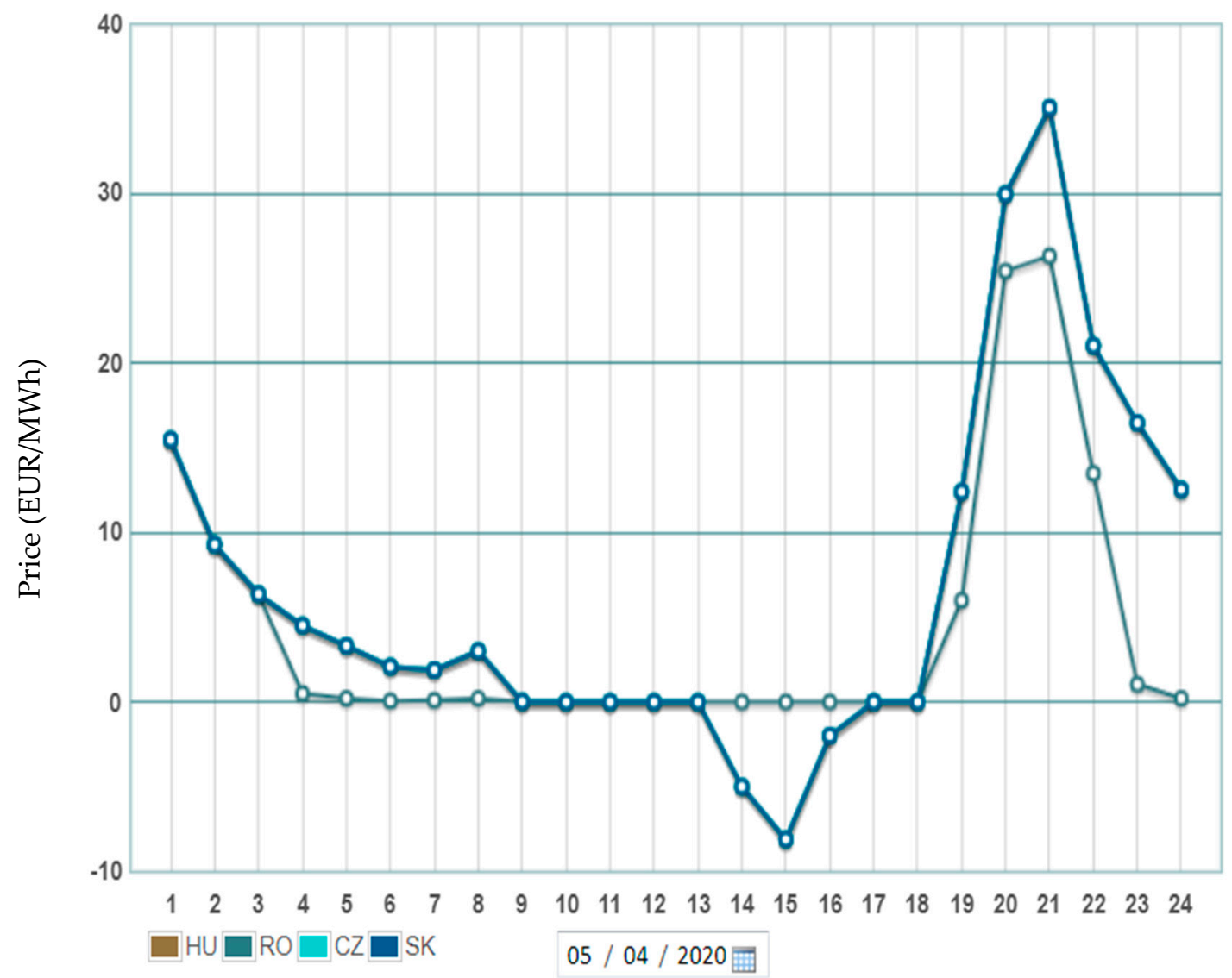

Figure 4. Low prices on coupled electricity markets at the RO-HU border (data processed from website: http://www.opcom.ro).

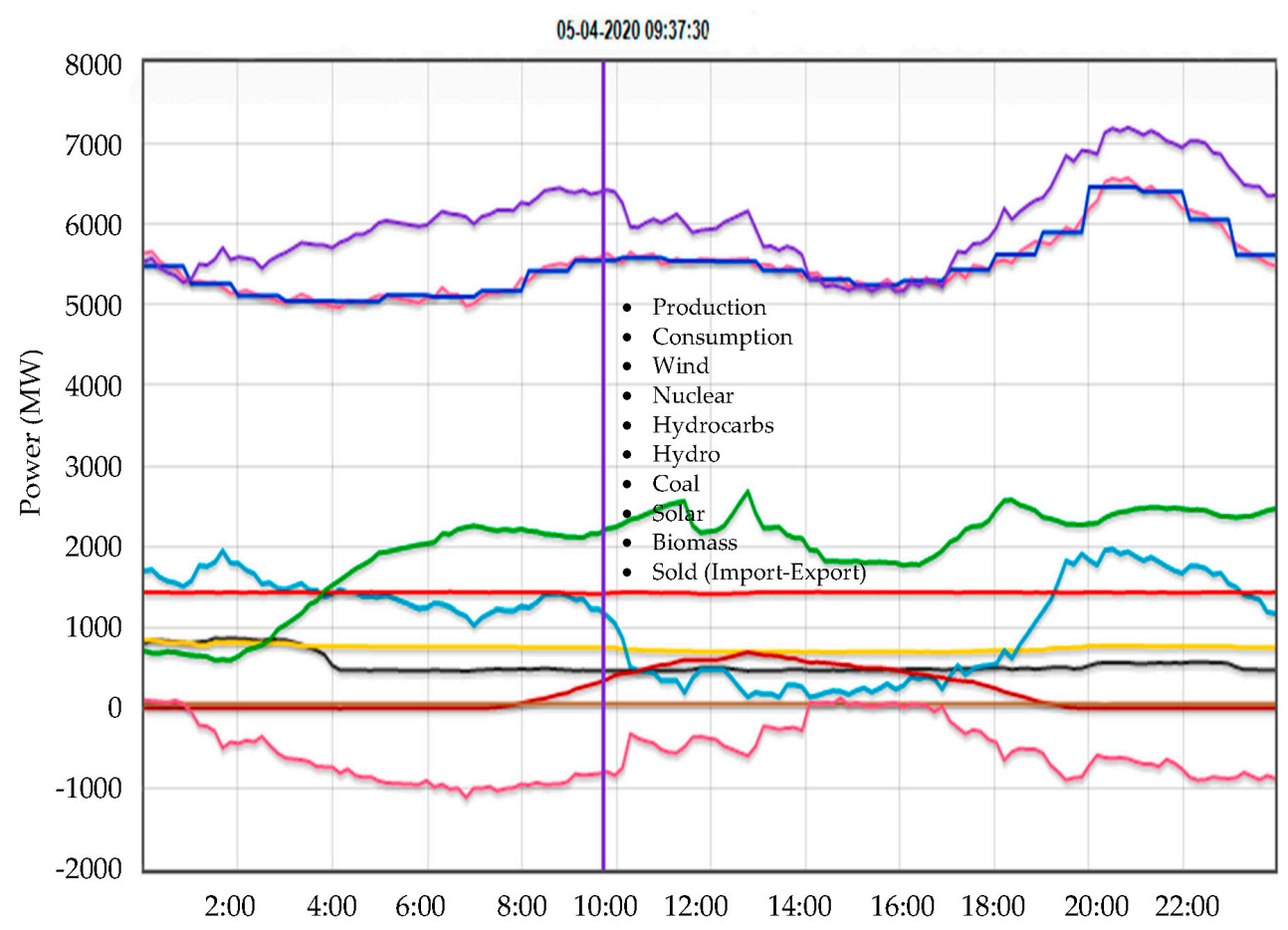

Figure 5. Electricity production in Romania on 5 April 2020 (data processed from website: http: //www.transelectrica.ro). 


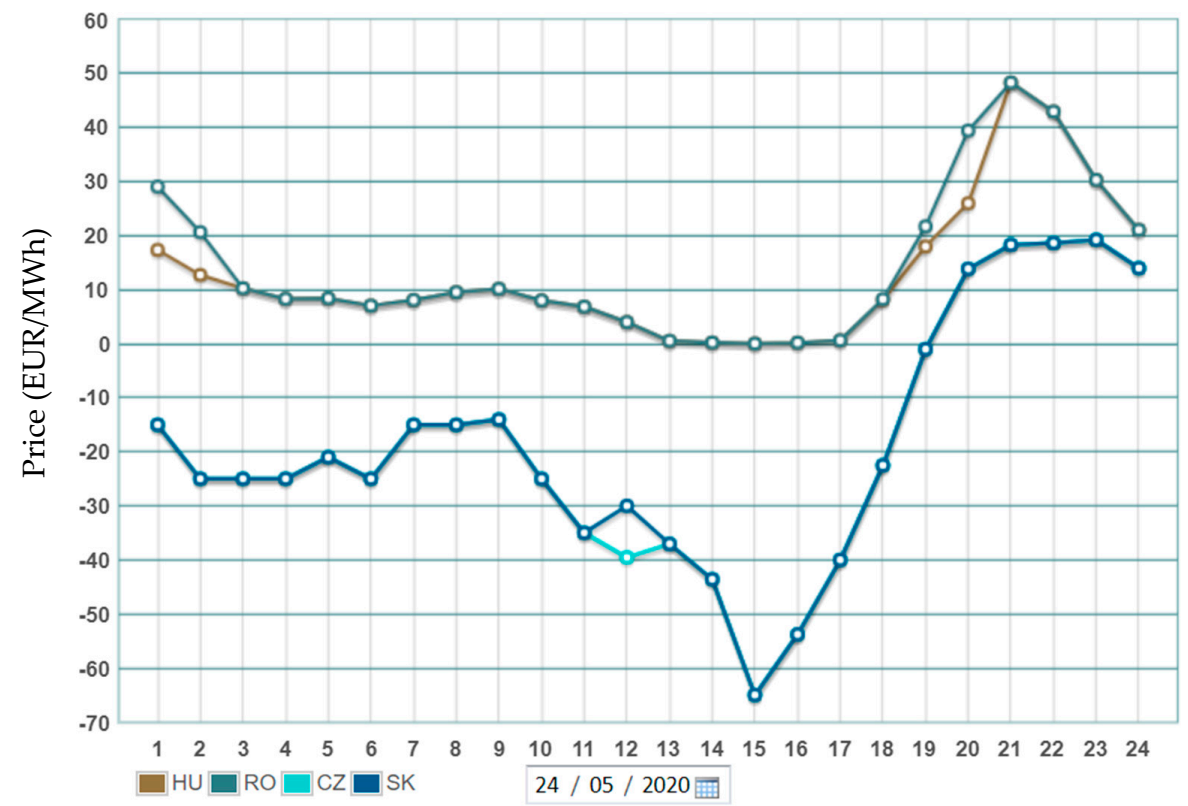

Figure 6. Negative prices on coupled electricity markets at the RO-HU border (data processed from website: http://www.opcom.ro).

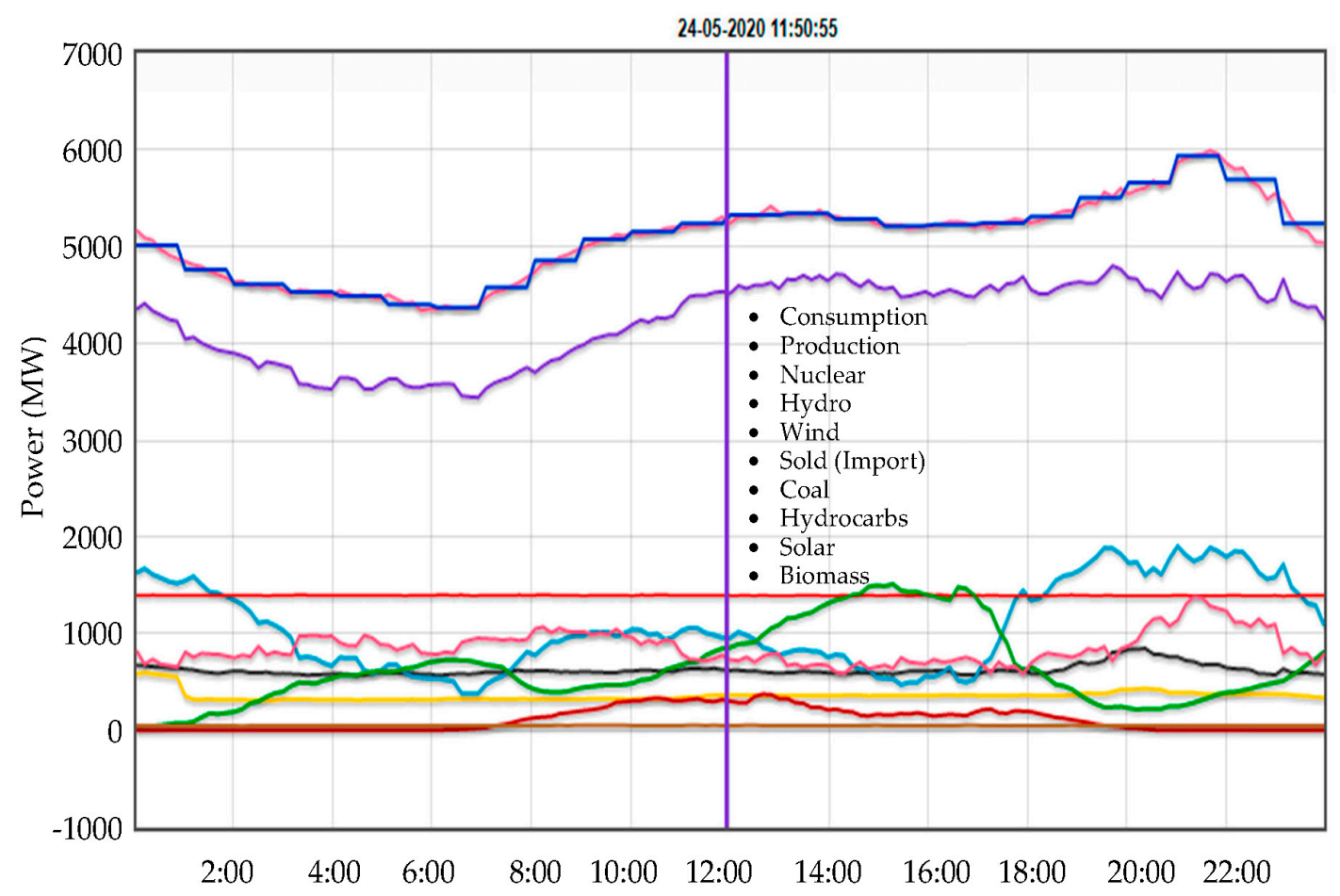

Figure 7. Electricity production in Romania on 24 May 2020 (data processed from website: http: //www.transelectrica.ro). 
Table 1. Characteristic values for coupling of the electricity markets on 19 September 2019.

\begin{tabular}{ccccccccc}
\hline \multirow{2}{*}{$\begin{array}{c}\text { Interval } \\
\text { Time }\end{array}$} & \multicolumn{5}{c}{$\begin{array}{c}\text { Price DAM } \\
\text { (EUR/MWh) }\end{array}$} & \multicolumn{5}{c}{$\begin{array}{c}\text { Cross-Border Flow } \\
\text { (MWh) }\end{array}$} & $\begin{array}{c}\text { Available Transmission Capacity } \\
\text { (MW) }\end{array}$ \\
\cline { 2 - 9 } & RO & HU & SK & CZ & RO_HU & HU_RO & RO_HU & HU_RO \\
\hline$\ldots$ & & & & & & & & \\
7 & 137.27 & 57.22 & 55.74 & 55.74 & 0 & 456 & 544 & 456 \\
8 & 147.83 & 60.60 & 55.75 & 55.74 & 0 & 456 & 544 & 456 \\
9 & 150.37 & 63.03 & 56.34 & 56.34 & 0 & 456 & 544 & 456 \\
10 & 149.51 & 58.95 & 51.18 & 51.18 & 0 & 456 & 544 & 456 \\
11 & 147.83 & 59.05 & 46.25 & 46.25 & 0 & 456 & 544 & 456 \\
12 & 158.39 & 55.12 & 44.00 & 44.00 & 0 & 456 & 544 & 456 \\
13 & 158.39 & 49.93 & 41.70 & 41.70 & 0 & 456 & 544 & 456 \\
14 & 148.04 & 49.94 & 41.00 & 41.00 & 0 & 456 & 544 & 456 \\
15 & 147.83 & 51.52 & 40.04 & 40.04 & 0 & 456 & 544 & 456 \\
16 & 148.04 & 54.94 & 40.41 & 40.41 & 0 & 456 & 544 & 456 \\
17 & 158.39 & 59.12 & 43.47 & 43.47 & 0 & 456 & 544 & 456 \\
18 & 148.04 & 63.46 & 49.68 & 49.68 & 0 & 456 & 544 & 456 \\
19 & 158.39 & 71.18 & 55.60 & 55.60 & 0 & 456 & 544 & 456 \\
20 & 158.39 & 66.00 & 71.18 & 71.18 & 0 & 456 & 544 & \\
21 & 158.39 & 58.08 & 62.70 & 62.70 & 0 & 456 & 544 & \\
$\ldots$ & & & & & & & & 456 \\
\hline
\end{tabular}

Table 2. Characteristic values for coupling of the electricity markets on 5 April 2020.

\begin{tabular}{|c|c|c|c|c|c|c|c|c|}
\hline \multirow{2}{*}{$\begin{array}{c}\text { Interval } \\
\text { Time }\end{array}$} & \multicolumn{4}{|c|}{$\begin{array}{l}\text { Price DAM } \\
\text { (EUR/MWh) }\end{array}$} & \multicolumn{2}{|c|}{$\begin{array}{l}\text { Cross-Border Flow } \\
\text { (MWh) }\end{array}$} & \multicolumn{2}{|c|}{$\begin{array}{c}\text { Available Transmission Capacity } \\
\text { (MW) }\end{array}$} \\
\hline & RO & HU & SK & $\mathrm{CZ}$ & RO_HU & HU_RO & RO_HU & HU_RO \\
\hline 7 & 0.10 & 1.89 & 1.89 & 1.89 & 530.0 & 0.0 & 530 & 470 \\
\hline 8 & 0.21 & 3.01 & 3.01 & 3.01 & 530.0 & 0.0 & 530 & 470 \\
\hline 9 & 0.02 & 0.02 & 0.02 & 0.02 & 398.7 & 0.0 & 530 & 470 \\
\hline 10 & 0.00 & 0.00 & 0.00 & 0.00 & 33.4 & 0.0 & 530 & 470 \\
\hline 11 & 0.00 & 0.00 & 0.00 & 0.00 & 101.0 & 0.0 & 530 & 470 \\
\hline 12 & 0.00 & 0.00 & 0.00 & 0.00 & 114.2 & 0.0 & 530 & 470 \\
\hline 13 & 0.00 & 0.00 & 0.00 & 0.00 & 0.0 & 143.2 & 530 & 470 \\
\hline 14 & 0.00 & -5.00 & -5.00 & -5.00 & 0.0 & 470.0 & 530 & 470 \\
\hline 15 & 0.00 & -8.12 & -8.12 & -8.12 & 0.0 & 470.0 & 530 & 470 \\
\hline 16 & 0.00 & -1.99 & -1.99 & -1.99 & 0.0 & 470.0 & 530 & 470 \\
\hline 17 & 0.00 & 0.00 & 0.00 & 0.00 & 0.0 & 176.4 & 530 & 470 \\
\hline 18 & 0.00 & 0.00 & 0.00 & 0.00 & 50.2 & 0.0 & 530 & 470 \\
\hline 19 & 6.00 & 12.42 & 12.42 & 12.42 & 530.0 & 0.0 & 530 & 470 \\
\hline 20 & 25.45 & 30.00 & 30.00 & 30.00 & 530.0 & 0.0 & 530 & 470 \\
\hline 21 & 26.35 & 35.11 & 35.11 & 35.11 & 530.0 & 0.0 & 530 & 470 \\
\hline$\ldots$ & & & & & & & & \\
\hline
\end{tabular}

Electricity generation and consumption must be balanced so that the market is balanced and does not collapse. When there is too much production, short-term markets tend to lower their prices or even have negative prices to discourage producers from generating.

Prices on the wholesale electricity market result from the meeting of supply (production) and demand (consumption). Basically, the higher the supply compared to the demand, the lower the price of electricity.

In these periods of overproduction, producers who cannot shut down their power plants have to pay to sell their production, while some large buyers are encouraged to consume more. These short-term movements have little influence on the bill of small consumers, as most individuals have fixed-term contracts for long periods of time. On the other hand, for large industrial consumers who have short-term contracts, this is an advantage, because they can buy electricity very cheaply, even at a negative price. 
Table 3. Characteristic values for coupling of the electricity markets on 24 May 2020.

\begin{tabular}{ccccccccccc}
\hline \multirow{2}{*}{$\begin{array}{c}\text { Interval } \\
\text { Time }\end{array}$} & \multicolumn{4}{c}{$\begin{array}{c}\text { Price DAM } \\
\text { (EUR/MWh) }\end{array}$} & \multicolumn{3}{c}{$\begin{array}{c}\text { Cross-Border Flow } \\
\text { (MWh) }\end{array}$} & \multicolumn{3}{c}{$\begin{array}{c}\text { Available Transmission Capacity } \\
\text { (MW) }\end{array}$} \\
\cline { 2 - 10 } & RO & HU & SK & CZ & RO_HU & HU_RO & SK_HU & RO_HU & HU_RO & SK_HU \\
\hline$\ldots$ & & & & & & & & & & \\
5 & 8.40 & 8.40 & -21.00 & -21.00 & 0 & 393.4 & 969.0 & 750 & 550 & 969 \\
6 & 7.05 & 7.05 & -24.99 & -24.99 & 0 & 426.8 & 969.0 & 750 & 550 & 969 \\
7 & 8.08 & 8.08 & -14.99 & -14.99 & 0 & 369.2 & 969.0 & 750 & 550 & 969 \\
8 & 9.54 & 9.54 & -15.00 & -15.00 & 0 & 432.1 & 969.0 & 750 & 550 & 969 \\
9 & 10.15 & 10.15 & -14.02 & -14.02 & 0 & 395.3 & 969.0 & 750 & 550 & 969 \\
10 & 8.01 & 8.01 & -25.00 & -25.00 & 0 & 261.8 & 969.0 & 750 & 550 & 969 \\
11 & 6.85 & 6.85 & -35.00 & -35.00 & 0 & 31.0 & 969.0 & 750 & 550 & 969 \\
12 & 4.00 & 4.00 & -30.00 & -39.54 & 0 & 138.5 & 969.0 & 750 & 550 & 969 \\
13 & 0.53 & 0.53 & -37.04 & -37.04 & 0 & 204.1 & 969.0 & 750 & 550 & 969 \\
14 & 0.21 & 0.21 & -43.59 & -43.59 & 0 & 187.0 & 969.0 & 750 & 550 & 969 \\
15 & 0.02 & 0.02 & -65.00 & -65.00 & 0 & 406.1 & 969.0 & 750 & 550 & 969 \\
16 & 0.20 & 0.20 & -53.79 & -53.79 & 0 & 338.6 & 969.0 & 750 & 550 & 969 \\
17 & 0.62 & 0.62 & -40.00 & -40.00 & 0 & 258.0 & 969.0 & 750 & 550 & 969 \\
18 & 8.25 & 8.10 & -22.50 & -22.50 & 0 & 550.0 & 969.0 & 750 & 550 & 969 \\
19 & 21.72 & 18.00 & -1.00 & -1.00 & 0 & 550.0 & 969.0 & 750 & 550 & 969 \\
$\ldots$ & & & & & & & & & & \\
\hline
\end{tabular}

Cross-border electricity exchanges use the available transmission capacity (ATC) on the border to reduce price differences between coupled electricity markets. Supply and demand are traded on the stock exchange until cross-border transmission capacity is exhausted or market prices are the same in both countries. These situations can be easily identified in Figure 2-Table 1 (on the SK-CZ border in time intervals 7-21); Figure 4-Table 2 (on the RO-HU-SK-CZ borders in the time intervals 10-13 and 17-18; on the HU-SK-CZ borders in the time intervals 7-9, 14-16 and 19-21); Figure 6-Table 3 (on the RO-HU border in time intervals 5-17; on SK-CZ borders in time intervals 5-21).

If the available transmission capacity on the border is reached before the price alignment, then electricity prices remain different: The other situations in Figure 2-Table 1; Figure 4-Table 2; Figure 6-Table 3.

Exports through interconnections and flexible consumption are not necessarily enough to reduce falling prices. If, at some point, electricity demand rises sharply and supply is difficult to maintain due to a lack of production supply, prices are rising because some suppliers are willing to pay a high price to avoid a blackout. If, on the other hand, demand is weak in the face of abundant supply, prices will fall.

Situations with negative prices certainly correspond to low marginal costs at a given time, but this does not mean that these prices make it possible to cover the total production costs of the installations concerned. This phenomenon can be amplified by the structure of certain support mechanisms for renewable production. Currently a large part of the production of electricity from renewable sources is supported by various schemes. Thus, support payments depend on the production of electricity achieved. Therefore, even when prices are negative it can be profitable for renewable producers to continue to operate.

\section{Conclusions}

Radical changes have taken place in the energy sector in recent years, with a clear trend of increasing the production of electricity from renewable energy sources and new challenges for the market participants. Thus, some wholesale electricity markets have faced episodes of negative prices. In these single market situations, it is the producers who pay the suppliers. Negative prices occur especially in periods of abundant production of electricity from renewable sources and low demand, situations in which certain conventional energy sources cannot operate below a technical minimum. Negative values of electricity prices were recorded in the markets of Hungary, the Czech Republic and Slovakia (a record negative value of -65 EUR/MWh being registered on the SK-CZ border). 
As well, the lack of the participants skills in developing adequate bidding strategies was one of the causes of the price increase.

The electricity prices on the Romanian Day Ahead Market are very variable between a minimum registered value (0 EUR/MWh) and a maximum registered value (158 EUR/MWh). No negative prices have been registered so far in Romania, however, the energy markets with which Romania operates in coupled regime register frequent situations with negative electricity prices.

However, negative wholesale prices are not good news. An increase in overproduction episodes creates uncertainty in the markets and reflects an imbalance. The main undesirable effect of these negative prices is that the market no longer sends the right signals to investors. This is equivalent to destroying value, as producers' revenues from the electricity market no longer cover real production costs. Electricity producers are no longer encouraged to invest in the renewal and expansion of new production capacity, and this can lead to a risk of shutdown during periods of high energy demand.

Coupling regional energy markets can partially solve these situations. Therefore, the imbalance of a system can be resolved by a neighboring system if the interconnections are not already used at their maximum capacity level.

After a strong period of development, it becomes necessary to review the mechanisms to support the development of electricity production from renewable energy sources. In the longer term and when renewable energy production systems reach a certain level of maturity, we can imagine that their development will depend much more on market mechanisms. For the time being, and because European targets are particularly ambitious, a first step towards avoiding these situations could be to stop paying support schemes in the event of negative wholesale prices or when renewable energies cause network congestion.

However, a positive effect of situations with lower or even negative prices in the electricity markets must be highlighted. The development of large-scale storage capacity will be able to be encouraged by such behavior of the electricity market. As well, more levers to increase the flexibility of electricity consumption will need to be activated. Some uses are easy to control, such as the thermal use of electricity (heating or cooling by heat pumps) or the recharging of electric vehicles.

Continuous improvement of electricity demand and supply forecasts, thanks to weather models, will make it possible to better predict imbalances in the electricity system and anticipate the use of levers to increase the flexibility of final energy consumption.

Author Contributions: Conceptualization, P.A. and R.D.P.; writing-review and editing, E.H. All authors have read and agreed to the published version of the manuscript.

Acknowledgments: This work was supported by a grant of the Romanian Ministry of Research and Innovation, CCCDI-UEFISCDI, project number PN-III-P1-1.2-PCCDI-2017-0404/31PCCDI/ 2018, within PNCDI III.

Conflicts of Interest: The authors declare no conflict of interest.

\section{References}

1. Hinderks, V.J.; Wagner, A. Factor models in the German electricity market: Stylized facts, seasonality, and calibration. Energy Econ. 2019, 85, 104351. [CrossRef]

2. Balibrea-Iniesta, J. Economic Analysis of Renewable Energy Regulation in France: A Case Study for Photovoltaic Plants Based on Real Options. Energies 2020, 13, 2760. [CrossRef]

3. Xydis, G.; Vlachakis, N. Feed-in-Premium Renewable Energy Support Scheme: A Scenario Approach. Resources 2019, 8, 106. [CrossRef]

4. Conteh, A.; Lotfy, M.E.; Adewuyi, O.B.; Mandal, P.; Takahashi, H.; Senjyu, T. Demand Response Economic Assessment with the Integration of Renewable Energy for Developing Electricity Markets. Sustainability 2020, 12, 2653. [CrossRef]

5. Maciejowska, K. Assessing the impact of renewable energy sources on the electricity price level and variability-A quantile regression approach. Energy Econ. 2019, 85, 104532. [CrossRef]

6. Pahle, M.; Schill, W.P.; Gambardella, C.; Tietjen, O. Renewable Energy Support, Negative Prices, and Real-time Pricing. Energy J. 2016, 37, 147-169. [CrossRef] 
7. Zhao, H.; Wang, Y.; Zhao, M.; Tan, Q.; Guo, S. Day-Ahead Market Modeling for Strategic Wind Power Producers under Robust Market Clearing. Energies 2017, 10, 924. [CrossRef]

8. Loumakis, S.; Giannini, E.; Maroulis, Z. Merit Order Effect Modeling: The Case of the Hellenic Electricity Market. Energies 2019, 12, 3869. [CrossRef]

9. Pezzutto, S.; Grilli, G.; Zambotti, S.; Dunjic, S. Forecasting Electricity Market Price for End Users in EU28 until 2020-Main Factors of Influence. Energies 2018, 11, 1460. [CrossRef]

10. Rashidizadeh-Kermani, H.; Najafi, H.R.; Anvari-Moghaddam, A.; Guerrero, J.M. Optimal Decision-Making Strategy of an Electric Vehicle Aggregator in Short-Term Electricity Markets. Energies 2018, 11, 2413. [CrossRef]

11. Roungkvist, J.S.; Enevoldsen, P.; Xydis, G. High-Resolution Electricity Spot Price Forecast for the Danish Power Market. Sustainability 2020, 12, 4267. [CrossRef]

12. Genoese, F.; Genoese, M.; Wietschel, M. Occurrence of negative prices on the German spot market for electricity and their influence on balancing power markets. In Proceedings of the 7th International Conference on the European Energy Market, Madrid, Spain, 23-25 June 2010.

13. Filho, J.C.R.; Tiwari, A.; Dwivedi, C. Understanding the Drivers of Negative Electricity Price Using Decision Tree. In Proceedings of the 2017 Ninth Annual IEEE Green Technologies Conference (GreenTech), Denver, CO, USA, 29-31 March 2017.

14. Brijs, T.; De Vos, K.; De Jonghe, C.; Belmans, R. Statistical analysis of negative prices in European balancing markets. Renew. Energy 2015, 80, 53-60. [CrossRef]

15. Price Coupling of Regions (PCR). Available online: http://www.epexspot.com/en/marketcoupling/pcr (accessed on 30 June 2020).

16. Romanian Power Market Operator. Available online: http://www.opcom.ro (accessed on 30 June 2020).

17. Romanian Power Grid Company. Available online: http://www.transelectrica.ro (accessed on 30 June 2020).

Publisher's Note: MDPI stays neutral with regard to jurisdictional claims in published maps and institutional affiliations. 